\title{
Moving from products to services: Supporting strategic thinking through design workshops
}

\author{
Olivia Harre ${ }^{*}$, Luca Simeone ${ }^{b}$, Lene Nielsena \\ alT-Univeristy of Copenhagen \\ ${ }^{\mathrm{D}} \mathrm{Aalborg}$ University of Copenhagen \\ *Corresponding author email: olih@itu.dk
}

\begin{abstract}
Transitioning a company from product-centricity to a new service-centred offering requires substantial changes, which can have deep implications for the company's processes, structure, and technology. Strategic thinking can help managers and employees to plan and cope with change. Our paper offers empirical insight into how a Danish IT company that is transitioning to being service-centric hosted and facilitated a set of design workshops to foster strategic thinking across the organization. Such design workshops were structured to invite participants to adopt multiple perspectives and think through different temporalities, while mediating the interaction to allow diverse perspectives to emerge.
\end{abstract}

Keywords: strategic thinking; design workshops; service centricity

\section{Introduction}

We live in a time of profound changes and socio-economic crises, which challenge organizations and companies to rethink and adapt their business models to encompass the impact of uncertainty. Planning for proactive long-term strategies and new ways to depict and represent future possibilities for strategic positioning is necessary (Buehring \& Bishop, 2020). Strategic thinking has been proposed as a core capability of companies to be adaptive and drive sustainable strategies (Srivastava \&

D'Souza, 2021).

Previous research has been attentive towards how components of design can support organizations in their strategizing practices (Buehring \& Liedtka, 2018; Liedtka \& Mintzberg, 2006), e.g. researchers have proposed that design can play a significant role in how organizations plan, decide and act to influence and take a more emergent approach to the future (Buehring \& Bishop, 2020). Specifically, design tools have been proposed as approaches to help frame relevant issues and favour the emergence of creative possibilities to address these issues; the fact that the processes tend to rely on prototyping and other design representations give organizations the possibility to engage and 
experiment with an array of possible and desirable futures (Buehring \& Liedtka, 2018; Elsbach \& Stigliani, 2018).

Empirical studies on how design thinking can effectively back strategy formulation and development exist within design research (Elsbach \& Stigliani, 2018; Liedtka, 2000; Liedtka \& Mintzberg, 2006). Some of these studies examine how specific design tools or processes can support the practice of strategic management (e.g. Eppler \& Platts, 2009; Heracleous \& Jacobs, 2008; Knight et al., 2020). However, fewer studies have focused explicitly on the construct of strategic thinking. Indeed, design research has rarely engaged with the various models of strategic thinking elaborated in management studies (Bonn, 2005; Liedtka, 1998; Srivastava \& D'Souza, 2021). As such, the specific ways in which design can support strategic thinking - and cultivate organizational transitioning from product centricity to services - remain underexplored.

This paper is grounded in a case study - a globally operating Danish software company that delivers a business-to-business enterprise solution. Within this organization, a new design team was established and asked to facilitate workshops where employees had to reflect on how core processes of the company could be restructured (from being product-centered to being service-centered). Within this context, design was valued as an approach to embrace and test future directions (Buchanan, 1992; Lalaounis, 2018) and to experiment with new business models (Hands, 2018). This case study gave us the opportunity to investigate the following question: How can design workshops support strategic thinking in an organization transitioning from product-centricity to services?

The remaining of the paper is organized as follows. In section 2 we present literature on strategy and strategic thinking and connect these concepts with design. Section 3 introduces the case study, which is followed by a more granular analysis in section 4. Lastly, we discuss our findings in section 5 and briefly conclude in section 6 .

\section{Related work}

\subsection{Strategy and strategic thinking}

While providing an overview of prominent conceptualizations of strategy in history, Freedman characterizes strategy as "[about] maintaining a balance between ends, ways, and means; about identifying objectives; and about the resources and methods available for meeting such objectives" (Freedman, 2013, xi). Core aspects of strategy relate to the resources and capabilities ('means') available (or that can be achieved and developed) and to defining goals and objectives ('ends') that can be realistically met by mobilizing these resources and capabilities in specific manners ('ways') (Simeone, 2020). Rumelt (2011) proposes a way to operationalize strategy and states that "the core of strategy work is always the same: discovering the critical factors in a situation and designing a way of coordinating and focusing actions to deal with those factors" (Rumelt, 2011, 3).

Strategic thinking is that specific way of thinking oriented towards identifying such critical factors and articulating and executing strategy (i.e., by balancing means, ends and ways) (Stubbart, 1989). Especially within management and organizational studies, several authors tried to define strategic thinking and the core characteristics of it. Liedtka (1998) proposes that strategic thinking can be described through five elements: 1) keeping a systems perspective, 2) focusing on a clear intent, 3 ) being open to emergent and unplanned opportunities, 4) thinking in time by imagining how past, present and future can be connected, 5) proceeding through cycles of hypothesis generation and testing (Liedtka, 1998). Liedtka's work is interesting because it highlights that even if strategic thinking is something that individuals do, organizational structure and processes can both constrain 
and enable individuals in their strategy practice (Liedtka, 1998; see also Mintzberg, 1978). Following this line of thought, a recent study has been presented by Bonn (2005), who highlighted the importance of designing organizational processes at the group level to enable individuals to jointly think strategically. Bonn (2005) sees strategic thinking as emerging from the combination of three aspects: 1) systems thinking, 2) creative thinking and 3) vision orientation thinking (Bonn, 2005). Consequently, thinking strategically implies the ability to manage the tensions that can occur, for example, when different views (e.g., present vs. future or zooming in and out on a problem) are required to elaborate fully on the complexity of systems. When these tensions are managed and nurtured through a "paradoxical thinking" (Calabretta et al., 2017) that brings together intuitive and rational thinking, they can be vital in driving strategic decision making. Tensions are also indicated in a recently proposed consensus model of the core dimensions of strategic thinking by Srivastava \& D'Souza (2021). The authors suggest operationalizing strategic thinking through three core dimensions: (a) systems thinking, (b) the "divergent thought processing", i.e., the idea that strategic thinking must adopt and integrate different views to comprehend and elaborate organizational complexity and (c) the "reflection" dimension, in which divergent and competing views and hypotheses are reconciled. We find this conceptualisation particularly helpful because it represents strategic thinking as a process that - like in the case of some prominent characterizations of design (Brown, 2009; Cross, 1985) - unfolds through phases of divergent and convergent thinking.

\subsection{Linking design and strategy}

Especially in the past two decades, researchers have pinpointed several ways in which design processes and artefacts can broadly support strategy (Ewenstein \& Whyte, 2009; Kaplan, 2010) and strategy-related ideation sessions, often fostering the emergence of multiple and divergent perspectives (Eppler \& Platts, 2009). Design approaches have been suggested as ways that could help managers and strategists make better business decisions and approach risks (Elsbach \& Stigliani, 2018; Liedtka, 2014) and design has indeed been characterized as an integral resource to corporate success (Lockwood, 2010). Design thinking has been compared to Liedtka's (1998) strategic thinking (Elsbach \& Stigliani, 2018) and design skills are proposed as central to management practices (Bonn, 2005; Liedtka, 2000) as part of a call for a new paradigm in business strategy (Boland \& Collopy, 2004; Cooper et al., 2011; Elsbach \& Stigliani, 2018; Liedtka \& Mintzberg, 2006). Particularly, design thinking has gotten much attention as an approach composed of specific tools that can be systematically applied to support strategy development in organizations (Elsbach \& Stigliani, 2018; Liedtka, 2014), through an iterative creative process that allows for identifying opportunities and learning through visualizations and prototyping (Knight et al., 2020; Liedtka \& Kaplan, 2019). Moreover, design thinking has been considered as an effective instrument to reduce those cognitive biases (Liedtka, 2014) that might affect strategic decisions (Acciarini et al., 2020; Hirshleifer, 2008). The link between design and strategy has also been closely scrutinized by researchers linked to design management (Lockwood, 2008) and strategic thinking has been characterized as an important capability in the process of building effective design goals and strategy and transforming a business (Lockwood, 2009). However, while researchers have studied and argued for the support of design in relation to developing and executing strategy, not many studies were directed towards a more finegrained investigation of the construct of strategic thinking. Our work aims at providing a contribution to this understudied area by linking design and strategic thinking and, particularly, by enriching the understanding of how design workshops can support the development of strategic thinking. 


\subsection{The format of design workshops}

Departing from the recent consensus model elaborated by Srivastava \& D'Souza (2021), our paper aims to give empirical insights as to how some characteristics of design workshops can help support the three dimensions of strategic thinking (systems thinking, divergent thought processing and reflection). The particular focus on the format of design workshops emerged by surveying recent literature. In this paper, our specific interest is in exploring the format of design workshops as part of sustaining a new design practice in an organization. Design workshops are emphasized as an essential part of the design process (Westerlund, 2007) and can be easily operationalised both in terms of resource, effort and activities needed (Stickdown \& Schneider, 2012). Design workshops are typically characterised by a collaborative, participatory aspect (Westerlund, 2007) whereby users and designers co-design (Sanders \& Stappers, 2008). However, for a service organization, the inclusivity of people has broadened to also include internal members of organizations that enable the service delivery (Polaine et al., 2013). Design workshops have been found to be effective in setting a space where company workers can produce knowledge about strategic issues (Paroutis et al., 2015) and articulate a service strategy (Harre \& Nielsen, 2020).

However, the risk with such a format is that these design workshops remain the only moments in which the participants and the whole company employ a design approach. This makes it difficult for design to become a key component of the organizational culture (Elsbach \& Stigliani, 2018). For a design practice to be sustained in the long run, researchers have found that there is value in building internal design capabilities to avoid "one-off" design projects (Holmlid \& Malmberg, 2018; WetterEdman \& Malmberg, 2016). Sustained design practice is of vital importance to support organizations in moments of profound change (like the shift from product- to service-centricity of our case study company), which affects employees' work practice, terminology, and routines (Kurtmollaiev et al., 2018).

In summary and connecting the threads elaborated in this literature review, this paper intends to explore the following research question: How can design workshops support strategic thinking in an organization transitioning from product-centricity to services?

\section{Research methods and case description}

The study uses a single-case study approach (Yin, 2018) to richly describe a phenomenon within reallife contexts (Eisenhardt \& Graebner, 2007) and explore the space between theory and experience of practice (Breslin \& Buchanan, 2008).

The case company is a globally operating software organisation that successfully delivers a businessto-business solution to financial professionals. Recently, the company embarked on an ambitious journey to change towards being service-centric and emphasized that their processes and vision focus on delivering holistic customer outcomes through software and related service offerings.

The first author of the study maintains a part-time engagement with the design team of the case company, and this gave the chance to collect empirical material over the period of 24 months. Taking an ethnographic approach, the first author has been a participant-observer with full participation (Spradley, 1980) in all workshops and meetings in between. She is still employed in the company and, therefore, highly immersed in her role as both insider and outsider (Bruskin, 2019) by "shadowing" the design team as a source of insights (Czarniawska, 2008).

In 2020, the case company organized five design workshops aimed at various teams in different business areas. The scope of these workshops was to gather participants and jointly reflect on 1 ) 
defining a new vision for the team with regards to the broad company orientation, 2) analysing the current problems specific to the projects' business areas that motivate the transition from products to services, 3) understanding the assumptions and risks of this transition, as well as 4 ) the internal resources needed. The workshops were framed in relation to how the company's new strategic direction was articulated in the product management department, where the design team is established. The workshops initiated how core processes could be restructured to focus on customer outcomes. The team was asked to facilitate workshops with representatives from across the organisation, organized in five project teams. The workshops combined presentations with group activities and were structured around similar core characteristics (see Figure 1).

\section{CHARACTERISTICS OF THE WORKSHOPS}

\section{Aim}

The overall purpose of the workshops was to build team cohesion, mostly through a shared understanding of the key strategic aspects of the shift from a product- to a service-oriented approach. In practice, each workshop focused on one of the current key IT development projects of the case company. The workshops helped participants develop strategic considerations in relation to problems, vision and risks and resources for each project.

\section{Format}

All the workshops followed the same format (i.e. timeboxed activities that used predefined canvases and other visual material to support collaborative brainwriting and storytelling oriented towards identifying potential causes for success and failure of the project by deliberately adopting multiple and divergent perspectives).

\section{Participants}

5-13 per workshop (excl. 4 designers); participants were selected as to represent different organizational functions. Each team consisted of different participants linked to the project across similar departments (e.g. Market Unit, Services, R\&D).

\section{Duration}

90-120 minutes per workshop

Figure 1: Core characteristics of the workshops

There was no logical order of the workshops, but the five projects selected were the result of a prioritization process undertaken by senior management. The specific format of the workshops was chosen to favour participatory dynamics within teams consisting of multiple disciplines and organizational functions. In addition, the techniques were selected with the aim of gathering multiple perspectives in a way that allowed for equal participation.

The arguments presented in this paper draw on multiple sources of data centred around five workshops. In the following, we elaborate on how the workshops were organized and structured.

\section{Analytical description of the workshops}

\subsection{From a product-centered view to a user-centered view}

Following the first workshop, designers noticed similarities in how the current problem was perceived and described by participants. The manager explained that this could be due to the fact that participants were deeply ingrained in organizational processes and routines and that their view 
was preconceived and biased. The manager linked the consensus view to frustrations that the participants accumulated over the years from not being able to serve the client needs; this has led to a strong belief that 9 team members already know how to solve the challenges. From this, the manager emphasized that the design workshop should be oriented towards breaking this way of thinking. Consequently, the design team included activities in the workshops in which participants were asked to adopt the perspective of a single, specific end-user and to empathize with their needs and wants. To break group biases, the workshop participants were asked to work on this exercise independently. In other words, the workshops were trying to break the participants' existing view (i.e., the team in charge of the product knows best how to develop and maintain the product) and to invite the participants to look at the product offering through the lens of a user-centered perspective. Adopting such a user-centered view was a new approach for most of the participants and aimed at shifting their way of seeing things, making them more open to accept the need to change the current company processes.

\subsection{Deliberately including multiple perspectives}

As a follow up exercise, participants were asked to formulate both the problem that could be solved by the company's software and the vision on how to address this problem from the perspective of multiple users outside of the organization. This was done by asking the participants to work individually and complete a short narrative. It was important that the participants did not focus on the same user profile but rather considered multiple perspectives (e.g., a specific work role, customer, or customer segment). For example, as an activity to establish a shared understanding of the perception of the current problem, the following narrative template was completed (Figure 2).

\section{DEFINE PROBLEM}

\section{The current [process/workflow/solution] is leading to [negative business result] because [specific people] currently can't [measurable behavior]}

The current [solution A] with workarounds is leading to operational risks and poor workflows because [work roles $B$ and $C$ ] cannot manage [functionality $D$ ] and are exposed to signitfact operational risk

Figure 2: Template (left) and example from workshop 2 (right)

The exercise uncovered similar patterns across all five project workshops showing how the current solution was described as inefficient manual processes, workarounds and operational risks. Figure 2 shows an example of how a participant considered the current solution from various outsiders' perspectives (work roles $B$ and $C$ ) and inspired an empathetic aspect of the risks as seen by customers.

\subsection{Thinking across temporalities}

The storytelling activities in the workshops served as a frame for the participants to tinker with different temporalities. Starting with the current situation of the organization, the participants were asked to imagine a desirable future outcome emerging when completing the project (Figure 3). 
DEFINE VISION

We expect ... [the solution]

will be desired by [specific people]

as they will [measurable behaviour]

thus, leading to [positive business results]
We expect that [solution B] will be desired by [any work role offering functionality C] as they will be met with customer demands for [functionality C], thus leading to efficient management and governance of the [functionality $C$ ]

Figure 3 Template (left) and example from workshop 5 (right)

Figure 3 shows an example from workshop 5. The characteristic of thinking through temporalities did not only invite participants to focus on the service design of the solution but also pointed inward to organizational challenges of transitioning towards delivering projects with the new process.

Participants were invited to share assumptions of why the project might fail and how to mitigate the risks (Figure 4).

DEFINE ASSUMPTIONS \& RISK

The biggest risk we face is...

Imagine we see the future and it shows

we've failed: why?

What is the most important thing we need to learn?

Figure 4 Template

The pattern across workshops showed that participants worried about having enough resources and were curious to learn about the project's scope and to understand how the project might evolve into something that can have a bigger positive impact on the life of the customers and organization.

\subsection{Mediating the interaction}

The third characteristic focuses on techniques that invited participants to engage on equal terms. The interaction in the workshops was mediated by using a virtual tool and activities. The group exercises were all completed by using a timeboxed structured brainwriting approach. As a technique, brainwriting helped build shared understanding amongst participants. In timeboxed sessions, each participant was asked to complete a sentence independently. This technique meant that each participant was given a set time to complete a writing prompt and then a set time to read aloud their stories to the team. The mediated format helped establish a space where each participant took part on equal footing and created a sense of collaboration. The virtual environment meant that participants could not physically see each other but 'hide' behind their virtual avatars. Nonetheless, participants demonstrated being at ease with expressing their hopes and frustrations from being part of the project team. For example, one participant noted down that they were struggling in front of clients (workshop 4). The workshops offered a "safe" or "open" space to vet fears and concerns while also allowing participants to speak their minds and share ideas on how to reframe the current situation. 


\section{Discussion}

Transitioning a company from product centricity to being service-centric requires substantial changes. These changes can have deep implications for the company's processes, structure, and technology. But, more importantly, the transition can affect employees' mindsets and routines. The ability to think strategically has been proposed to help individuals during times of uncertainty. Our study extends and contributes to existing work on strategic thinking (Srivastava \& D'Souza, 2021) by showing how characteristics of design workshops can support individuals to think in a strategic way about a company transition. We elaborate on our argument below.

\section{Including multiple perspectives}

Delivering an enterprise software solution to a diverse customer segment operating in a complex environment requires multiple disciplines to collaborate and a holistic, empathetic understanding of customer's challenges. For a company transitioning to services, it is important to integrate an outside-in perspective in its organizational processes (Polaine et al., 2013). The workshops encouraged participants to think beyond a current situation and created a safe space where participants could bring and appreciate multiple, contrasting perspectives on the project. This means that participants were asked to not consider the product itself, but to consider it from the perspectives of someone else. This brought forward a diversity of views both external to the project (e.g., customers, end-users) as well as internal voices (management, other team members). This multiplicity broke the participants' pre-existing cognitive biases (Liedtka, 2014) and rendered the company offering as a complex system, whose functioning depends on the views and actions of a multitude of actors with their own needs and wants. As such, exposing and inviting participants to include multiple perspectives supports the systems-thinking dimension (Srivastava \& D'Souza, 2021) as participants shifted between zooming in on internal perspectives within the organization and zooming out on external perspectives, such as the market. An important aspect of systems thinking is precisely the ability for managers to develop an understanding of interdependencies within the organization and across organizations (Srivastava \& D'Souza, 2021).

\section{Tinkering with temporalities}

Adopting and integrating divergent views is an important aspect of strategic thinking (Srivastava \& D'Souza, 2021). Aside from embracing multiple, contrasting perspectives on the projects, the workshops also tinkered with contrasting temporalities. The changes of a company in transition towards a new way of operating can unfold along multiple trajectories. By using a hypothesis-driven approach in the workshops, participants diverged into possible ways in which the project could unfold and competing perspectives were compared. Participants were guided through exercises that, at times, were grounded in the present while other times considered future possibilities. In this way, the format of the workshops probed participants to play with different time horizons through juxta positioning, e.g., the current situation vs. a vision for the future, what we know vs. what we do not know, risky assumptions vs. learnings needed. Through this format, the workshops fostered and supported the 'divergent thought processing' dimension (Srivastava \& D'Souza, 2021) as participants included and compared multiple perspectives and opportunities while also selecting and deciding how to progress. The outcomes of the workshops (e.g., considerations on problems, visions, assumptions and risks) allowed for the identification and inclusion of diverse perspectives that assessed the organizational situation.

\section{Mediating the interaction}

Through mediated interaction, the workshops created a space for participants to safely share their beliefs and perceptions related to the restructuring of a process focusing on being service-centric. Through storytelling techniques, participants were offered an opportunity to share their experiences 
in a way that balanced reality with imagination. The fictional aspect of these stories helped mediating participants' frustrations and critiques, as the stories offered sufficient distance from the participants' reality and mediated a space through which sharing experiences could be done in a less direct way. While scenarios and narratives are common design tools (Buehring \& Bishop, 2020; Stickdown \& Schneider, 2012), our case showed that they can also help to translate individuals' tacit knowledge in a more explicit way. As such, they can support individuals in their reflective thinking dimension (Srivastava \& D'Souza, 2021) as they expose participants to other participants' perspectives while also reflecting on their own.

The format and use of virtual tools gave participants equal access to discuss and share hopes, dreams and fears in transitioning the company towards services. The workshops supported a collaborative reflective practice as individuals were invited to complete the storytelling prompts in writing by building on their knowledge about the projects and the organizational situation. In turn, these reflective components allowed for team collaboration and interactions with the experiences of other participants.

\section{Conclusion}

To conclude, for an organization transitioning from product centricity to services, we have argued that design workshops can support three dimensions of strategic thinking (systems thinking, divergent thought processing and reflection) by (1) deliberately pushing participants to adopt a view of their organization as a complex, multi-perspective system, (2) by inviting them to think through different temporalities and (3) by creating a safe space for expression and collaborative reflections.

We qualify this study as preliminary and acknowledge the limitations of our findings. For future research, it would be relevant to look more deeply into some of the specific tensions that can be elicited by design. In this sense, theoretical conceptualizations on creating productive tensions (Calabretta et al., 2017) or on the co-existence of multiple characterizations of temporalities (Czarniawska, 2004) can be used as analytical lenses to go deeper into our study.

\section{References}

Acciarini, C., Brunetta, F., \& Boccardelli, P. (2020). Cognitive biases and decision-making strategies in times of change: a systematic literature review. Management Decision, 59(3), 638-652. https://doi.org/10.1108/MD-07-2019-1006

Boland, R. J., \& Collopy, F. (Eds.). (2004). Managing as Designing. Stanford University Press.

Bonn, I. (2005). Improving strategic thinking: A multilevel approach. Leadership \& Organization Development Journal, 26(5), 336-354. https://doi.org/10.1108/01437730510607844

Breslin, M., \& Buchanan, R. (2008). On the case study method of research and teaching in design. Design Issues, 24(1), 36-40. https://doi.org/10.1162/desi.2008.24.1.36

Brown, T. (2009). Change by Design. Harper Collins.

Bruskin, S. (2019). Insider or outsider? Exploring the fluidity of the roles through social identity theory. Journal of Organizational Ethnography, 8(2), 159-170. https://doi.org/10.1108/JOE-092017-0039

Buchanan, R. (1992). Wicked Problems Thinking in Design. Design Issues, 8(2), 5-21.

Buehring, J., \& Bishop, P. C. (2020). Foresight and Design: New Support for Strategic Decision Making. She Ji, 6(3), 408-432. https://doi.org/10.1016/j.sheji.2020.07.002

Buehring, J., \& Liedtka, J. (2018). Embracing systematic futures thinking at the intersection of Strategic Planning, Foresight and Design. Journal of Innovation Management, 6(3), 134. https://doi.org/10.24840/2183-0606_006.003_0006 
Calabretta, G., Gemser, G., \& Wijnberg, N. M. (2017). The Interplay between Intuition and Rationality in Strategic Decision Making: A Paradox Perspective. Organization Studies, 38(3-4), 365-401. https://doi.org/10.1177/0170840616655483

Cooper, R., Junginger, S., \& Lockwood, T. (Eds.). (2011). The Handbook of Design Management. Bloomsbury Academic.

Cross, N. (1985). Styles of Learning, Designing and Computing. Design Studies, 6(3), 157-162. https://doi.org/10.1016/0142-694X(85)90006-7

Czarniawska, B. (2004). On time, space, and action nets. Organization, 11(6), 773-791. https://doi.org/10.1177/1350508404047251

Czarniawska, B. (2008). Organizing: How to study it and how to write about it. Qualitative Research in Organizations and Management: An International Journal, 3(1), 4-20. https://doi.org/10.1108/17465640810870364

Eisenhardt, K. M., \& Graebner, M. E. (2007). Theory Building from Cases: Opportunities and Challenges. The Academy of Management Journal, 50(1), 25-32. https://doi.org/10.1007/BF01033590

Elsbach, K. D., \& Stigliani, I. (2018). Design Thinking and Organizational Culture: A Review and Framework for Future Research. Journal of Management, 44(6), 2274-2306. https://doi.org/10.1177/0149206317744252

Eppler, M. J., \& Platts, K. W. (2009). Visual Strategizing: The Systematic Use of Visualization in the Strategic-Planning Process. Long Range Planning, 42, 42-74. https://doi.org/10.1016/j.Irp.2008.11.005

Ewenstein, B., \& Whyte, J. (2009). Knowledge Practices in Design: The Role of Visual Representations as 'Epistemic Objects'. Organization Studies, 30, 07-30. https://doi.org/10.1177/0170840608083014

Freedman, L. (2013). Strategy: A History. Oxford University Press.

Hands, D. (2018). Design Management: The Essential Handbook. Kogan Page Limited.

Harre, O., \& Nielsen, L. (2020). From product centricity to services : Design workshops and maps as tools in strategy articulation. In Y. Akama, L. Fennessy, S. Harrington, \& A. Farrago (Eds.), ServDes.2020 - Tensions, Paradoxes, Plurality. Linköping University Electronic Press.

Heracleous, L., \& Jacobs, C. D. (2008). Crafting Strategy: The Role of Embodied Metaphors. Long Range Planning, 41, 309-325. https://doi.org/10.1016/j.Irp.2008.02.011

Hirshleifer, D. (2008). Psychological Bias as a Driver of Financial Regulation. European Financial Management, 14(5), 856-874. https://doi.org/10.1111/j.1468-036X.2007.00437.x

Holmlid, S., \& Malmberg, L. (2018). Learning to design in public sector organisations : A critique towards effectiveness of design integration. Service Design Proof of Concept, June, 38-48.

Kaplan, S. (2010). Strategy and PowerPoint: An Inquiry into the Epistemic Culture and Machinery of Strategy Making. Organization Science, 22, 320-346. https://doi.org/10.1287/orsc.1100.0531

Knight, E., Daymond, J., \& Paroutis, S. (2020). Design-Led Strategy: How To Bring Design Thinking Into The Art of Strategic Management. In California Management Review (Vol. 62, Issue 2). https://doi.org/10.1177/0008125619897594

Kurtmollaiev, S., Fjuk, A., Pedersen, P. E., Clatworthy, S., \& Kvale, K. (2018). Organizational Transformation Through Service Design: The Institutional Logics Perspective. Journal of Service Research, 21(1), 59-74. https://doi.org/10.1177/1094670517738371

Lalaounis, S. T. (2018). Design Management: Organisation and Marketing Perspectives. Routledge. Liedtka, J. (1998). Strategic Thinking: Can it be Taught? Long Range Planning, 31(1), 120-129.

Liedtka, J. (2000). In Defense of Strategy as Design. California Management Review, 42(3), 8-30. https://doi.org/https://doi.org/10.2307/41166040

Liedtka, J. (2014). Perspective: Linking Design Thinking with Innovation Outcomes through Cognitive Bias Reduction. Journal of Product Innovation Management, 32(6), 925-938. https://doi.org/https://doi.org/10.1111/jpim.12163

Liedtka, J., \& Kaplan, S. (2019). How design thinking opens new frontiers for strategy development. Strategy \& Leadership, 47(2), 3-10. https://doi.org/https://doi.org/10.1108/SL-01-2019-0007 
Liedtka, J., \& Mintzberg, H. (2006). Time for Design. Design Management Review, 17. https://doi.org/https://doi.org/10.1111/j.1948-7169.2006.tb00034.x

Lockwood, T. (2008). Building Design Strategy: Using Design to Achieve Key Business Objectives (T. Lockwood \& T. Walton (Eds.)). Allworth Press.

Lockwood, T. (2009). Transition: How to Become a More Design-Minded Organization. Design Management Review, 20(3), 28-37. https://doi.org/10.1111/j.1948-7169.2009.00019.x

Lockwood, T. (2010). Integrating design into organizational culture. Design Management Review, 15(2), 32-39. https://doi.org/10.1111/j.1948-7169.2004.tb00159.x

Mintzberg, H. (1978). Patterns of Strategy Formulation. Management Science, 24(9 (May)), 934-948.

Paroutis, S., Franco, L. A., \& Papadopoulos, T. (2015). Visual Interactions with Strategy Tools: Producing Strategic Knowledge in Workshops. British Journal of Management, 26(S1), S48-S66. https://doi.org/10.1111/1467-8551.12081

Polaine, A., Løvlie, K., \& Reason, B. (2013). Service Design: From Insight to Implementation. Rosenfeld Media.

Rumelt, R. (2011). Good Strategy, Bad Strategy. Crown Business.

Sanders, E. B.-N., \& Stappers, P. J. (2008). Co-creation and the new landscapes of design. CoDesign, 4(1), 5-18. https://doi.org/10.1080/15710880701875068

Simeone, L. (2020). Characterizing Strategic Design Processes in Relation to Definitions of Strategy from Military, Business and Management Studies. The Design Journal, 23(4), 515-534. https://doi.org/10.1080/14606925.2020.1758472

Spradley, J. P. (1980). Participant Observation. Waveland Press, Inc.

Srivastava, S., \& D'Souza, D. (2021). Measuring Strategic Thinking in Organizations. Journal of Managerial Issues, XXXIII(1), 90-111.

Stickdown, M., \& Schneider, J. (2012). This Is Service Design Thinking: Basics, Tools, Cases. John Wiley.

Stubbart, C. I. (1989). Managerial cognition: a missing link in strategic management research. Journal of Management Studies, 26, 325-347.

Westerlund, B. (2007). A Workshop Method that Involves Users Talking, Doing and Making. International Conference on Human-Machine Interaction, 98-102.

Wetter-Edman, K., \& Malmberg, L. (2016). Experience and Expertise: Key Issues for Developing Innovation Capabilities Through Service Design. ServDes.2016 Service Design Geographies; Proceedings from the Fifth Conference on Service Design and Service Innovation; Copenhagen 24-26 May 2016., 125, 516-521.

Yin, R. (2018). Case Study Research and Applications - Design and Methods. Sage Publications Inc.

Author Bios:

Olivia Harre is an industrial PhD student at IT University of Copenhagen and design practitioner conducting research in a Danish company examining the organizational transformative aspect of establishing internal service design practice.

Luca Simeone is an Associate Professor at Aalborg University and has conducted research and teaching activities in various universities (Harvard, MIT, Milan Polytechnic, Malmö University, University of the Arts London), mostly exploring the managerial, strategic, and organizational aspects of design.

Lene Nielsen is an Associate Professor at IT University Copenhagen, Department of Business IT. Her research interest covers user centricity and IT development within personas, agile development, and service design. She has written about 100 publications and books.

Acknowledgements: We would like to express our gratitude to the participants and supporters from the case company who helped make the research presented in this paper 
possible. We thank the reviewers for their helpful comments which helped us to refine the contribution of this paper and inspire future work. Lastly, we want to acknowledge the case company and Innovation Fund Denmark for funding the research project. 